\title{
UCRL-JRNL-209940
}

LAWRENCE LIVERMORE N A T IO N A L LABORATORY
Architecture and High-Resolution Structure of Bacillus thuringiensis and Bacillus cereus Spore Coat Surfaces

M.Plomp, T.J. Leighton, K.E. Wheeler, A.J. Malkin

February 24, 2005

Langmuir 
This document was prepared as an account of work sponsored by an agency of the United States Government. Neither the United States Government nor the University of California nor any of their employees, makes any warranty, express or implied, or assumes any legal liability or responsibility for the accuracy, completeness, or usefulness of any information, apparatus, product, or process disclosed, or represents that its use would not infringe privately owned rights. Reference herein to any specific commercial product, process, or service by trade name, trademark, manufacturer, or otherwise, does not necessarily constitute or imply its endorsement, recommendation, or favoring by the United States Government or the University of California. The views and opinions of authors expressed herein do not necessarily state or reflect those of the United States Government or the University of California, and shall not be used for advertising or product endorsement purposes. 


\section{Architecture and High-Resolution Structure of Bacillus thuringiensis and Bacillus cereus Spore Coat Surfaces}

Marco Plomp ${ }^{1}$, Terrance J. Leighton, ${ }^{2}$ Katherine E. Wheeler ${ }^{2}$ and Alexander J. Malkin ${ }^{{ }^{*}}$

${ }^{1}$ BioSecurity and NanoSciences Laboratory, Department of Chemistry and Materials

Science, Lawrence Livermore National Laboratory, L-234, Livermore CA 94551, USA

${ }^{2}$ Children’s Hospital Oakland Research Institute, Oakland, CA 94609, USA

\footnotetext{
*Corresponding author: Mailing address: BioSecurity and NanoSciences Laboratory, Department of Chemistry and Materials Science, L-234, Lawrence Livermore National Laboratory, Livermore CA 94551. Phone: (925) 423-7817; FAX: (925) 422-2041. Email: malkin1@llnl.gov
} 


\begin{abstract}
We have utilized atomic force microscopy (AFM) to visualize the native surface topology and ultrastructure of Bacillus thuringiensis and Bacillus cereus spores in water and in air. AFM was able to resolve the nanostructure of the exosporium and three distinctive classes of appendages. Removal of the exosporium exposed either a hexagonal honeycomb layer (B. thuringiensis) or a rodlet outer spore coat layer (B. cereus). Removal of the rodlet structure from $B$. cereus spores revealed an underlying honeycomb layer similar to that observed with $B$. thuringiensis spores. The periodicity of the rodlet structure on the outer spore coat of $B$. cereus was $\sim 8 \mathrm{~nm}$, and the length of the rodlets was limited to the cross-patched domain structure of this layer to $\sim 200 \mathrm{~nm}$. The lattice constant of the honeycomb structures was $\sim 9 \mathrm{~nm}$ for both $B$. cereus and $B$. thuringiensis spores. Both honeycomb structures were composed of multiple, disoriented domains with distinct boundaries. Our results demonstrate that variations in storage and preparation procedures result in architectural changes in individual spore surfaces, which establish AFM as a useful tool for evaluation of preparation and processing "fingerprints" of bacterial spores. These results establish that high-resolution AFM has the capacity to reveal species-specific assembly and nanometer scale structure of spore surfaces. These species-specific spore surface structural variations are correlated with sequence divergences in a spore core structural protein SspE.
\end{abstract}




\section{INTRODUCTION}

Atomic force microscopy (AFM) ${ }^{1,2}$ has emerged as a powerful technique to probe structural and physical properties of macromolecular ensembles ${ }^{3-10}$ and pathogen surfaces $^{11-19}$. AFM allows in vitro visualization of high-resolution native spore surface structures and their dynamic responses to changes in the environment. We have recently applied high-resolution in vitro AFM to the characterization of the surface architecture and structure of several species of Bacillus spores ${ }^{20,21}$. We have characterized the highresolution spore coat structure of both fully hydrated and air-dried spores of $B$. atrophaeus $^{21}$. We have also determined the structural dynamics associated with a change in the environment from fully hydrated to an air-dried state ${ }^{21}$.

In the present study, we have utilized AFM to characterize the architectural and structural features of Bacillus thuringiensis and Bacillus cereus spores. Previous electron microscopic studies have identified $B$. cereus exosporial appendages, spore surface crosspatched and underlying spore coat honeycomb structures ${ }^{22-27}$. B. thuringiensis contains a similar exosporium and honeycomb coat structure, yet lacks the cross patched rodlet layer $22,23,25,26$. These pioneering studies suggested the possibility of species-specific spore surface architecture ${ }^{23}$. However, the effects of sample preparation, freeze-etching and sectioning on native spore surface structures is unknown, and the described structural variations were not correlated with molecular phylogeny.

We have utilized high-resolution AFM to examine the crystalline layers of native B. thuringiensis and B. cereus spore surfaces from both fully hydrated and air-dried spores. The $B$. cereus species is environmentally ubiquitous and can cause bacterimia and septicemia, central nervous and respiratory system infections, endocarditis and food 
poisoning $^{28}$. The insect pathogenic B. thuringiensis species harbors extrachromosomal plasmids that encode insecticidal Cry proteins, which are localized in parasporal inclusions $^{29,30}$. B. cereus, B. thuringiensis and B. anthracis have been considered by some workers to be a single species ${ }^{31}$. Other workers ${ }^{29}$ have suggested that the single species concept does not account for the fact that cry gene plasmids have not been found in naturally occurring B. anthracis strains and that the natural genetic structure of sympatric B. cereus and B. thuringiensis populations were not considered. We demonstrate here that there are qualitative differences between the native spore coat surface structures of these two "species" that are consistent with previous observations ${ }^{23}$. In addition, we show that these ultrastructural variations are correlated with DNA and protein sequence variations in a spore structural protein gene $\operatorname{ssp} E^{32}$ which has been used to develop a highspecificity DNA-based assay for $B$. anthracis that is able to discriminate this species from near-neighbor B. cereus and B. thuringiensis strains.

\section{MATERIALS AND METHODS}

Bacterial strains and sporulation conditions. B. cereus T (6A1) and B. thuringiensis israelensis (ATCC 35646) were obtained from the Bacillus Genetic Stock Center and the American Type Culture Center respectively. Spore preparation and purification was performed as previously described ${ }^{33,34}$. For solid phase sporulation $1.5 \%$ agar was added to Schaeffer's sporulation medium ${ }^{35}$ and the plates were incubated at $37^{\circ} \mathrm{C}$ for $B$. cereus or $30^{\circ} \mathrm{C}$ for $B$. thuringiensis israelensis, until confluent sporulation was achieved.

DNA preparation and sspE PCR conditions. Genomic DNA was prepared and purified using the Easy DNA kit (Invitrogen, CA, USA). PCR primers were designed using the 
Primer3 algorithm (S. Lincoln, M.J. Daly, E.S. Lander, Whitehead Institute) and their sequences are shown in Table 1. The primers were designed to amplify a fragment of approximately 340 base pairs containing the entire $s s p E$ coding and surrounding regulatory sequences. Each $50 \mu \mathrm{l}$ PCR reaction mixture contained $5 \mu \mathrm{l}$ 10X Buffer (w/15 $\mathrm{mM} \mathrm{MgCl}_{2}$ ) (Qiagen), $200 \mu \mathrm{M}$ of each dNTP (Invitrogen), $25 \mathrm{pm} / \mu \mathrm{l}$ of each primer (MWG Biotech), 1.25U AmpliTaq enzyme (Qiagen), and approximately $100 \mathrm{ng}$ of template DNA. Amplicons were obtained with a PCR cycling program (Applied Biosystems GeneAmp ${ }^{\circledR}$ PCR System 9700 ) of $94^{\circ} \mathrm{C}$ for 5 minutes, 35 cycles at $94^{\circ} \mathrm{C}$ for 30 seconds, $55^{\circ} \mathrm{C}$ for 30 seconds and $72^{\circ} \mathrm{C}$ for 30 seconds. At the end of thermocycling, PCR reactions were incubated at $72^{\circ} \mathrm{C}$ for 7 minutes. Amplicons were visualized by electrophoretic separation on $2 \%(\mathrm{w} / \mathrm{v})$ agarose (Invitrogen UltraPure ${ }^{\mathrm{TM}}$ Agarose) gels stained with ethidium bromide (Sigma) at a final concentration of $5 \times 10^{-4} \mathrm{mg} \mathrm{EtBr} / \mathrm{ml}$ gel solution.

sspE DNA sequence and data analysis. PCR fragments were purified from amplification reactions with QIAquick PCR purification reagents (QIAGEN). DNA sequences were obtained from Elim Biopharmaceuticals (Hayward, CA). The $s s p E$ sequence data obtained in this work have been deposited in the GenBank nucleotide sequence database with accession numbers AF359764-AF359938. Computational analysis of DNA sequence data, sequence editing and multisequence alignment were performed using DNAstar and Biology WorkBench programs (CLUSTALW alignment and TEXSHADE).

Table 1. PCR primer sequences 


\begin{tabular}{|l|l|}
\hline \multicolumn{1}{|c|}{ Primer } & \multicolumn{1}{c|}{ Sequence (5' to 3 ') } \\
\hline Fc2 & AAGTGAATTGGTTACATTATTGATTGT \\
Rt2 & ATTGGAGAAGTGTTTTTCTTTCA \\
\hline
\end{tabular}

Spore nano-dissection methods and AFM measurements. Removal of the spore exosporium and the outer spore coat was conducted using a 20kHz 130W Vibra-cell VC 130 (Sonics \& Materials, Newtown, CT) sonicator with a $3 \mathrm{~mm}$ probe. Spore suspensions were sonicated in an Eppendorf tube for 5 seconds, interspersed with 20-second cooling intervals $\left(4^{\circ} \mathrm{C}\right)$ to prevent excessive heating of the sample. Typically spore samples were treated for 10-20 cycles of sonication. During each cycle the sonication amplitude was increased from 0 to $30 \%$ and subsequently decreased to $0 \%$ for the removal of the exosporium. For the removal of both the exosporium and the outer spore coat sonication amplitudes were typically increased to 50\%.

For AFM imaging droplets of spore suspension $(0.5-3 \mu \mathrm{l})$ were deposited directly onto a substrate and were allowed $\sim 5$ minutes to settle, after which the sample substrate was carefully rinsed with double distilled water. For imaging of air-dried and fully hydrated spore samples, freshly cleaved mica and polycoated vinyl plastic respectively were utilized as a substrate. For imaging in air, the samples were dried and imaged. For imaging in water, the substrates with deposited spore samples were transferred to the AFM fluid cell, which was subsequently filled with water.

Images were collected using a Digital Instruments Multimode Nanoscope IIIa and IV atomic force microscopes (Digital Instruments, Santa Barbara, CA) operated in tapping mode. Height, amplitude and phase images ${ }^{36}$ were typically recorded simultaneously. 
Commercially available etched silicon tips (force constants of $\sim 40 \mathrm{~N} / \mathrm{m}$ and resonance frequencies of $\sim 300 \mathrm{kHz}$ ) and oxide-sharpened silicon nitride tips (force constants of approximately $0.1 \mathrm{~N} / \mathrm{m}$ and resonance frequencies of $\sim 9 \mathrm{kHz}$ ) were employed for imaging in air and fluid, respectively.

\section{RESULTS AND DISCUSSION}

Size distribution of air-dried spores of Bacillus thuringiensis and B. cereus. AFM images of air-dried B. thuringiensis and B. cereus spores are presented in Fig. 1. Length and width measurements of solution-grown and plate-grown B. thuringiensis air-dried spores were based on samples of 50 spores and 150 spores, respectively ${ }^{20}$. For solutiongrown spores, length ranged between $1.6-2.5 \mu \mathrm{m}$ with an average $\mathrm{L}_{\mathrm{av}}$ of $2.0 \mu \mathrm{m}$ (absolute deviation $\mathrm{AD}=7.8 \%$ ) and width ranged within $750-1000 \mathrm{~nm}$, width an average width $\mathrm{W}_{\mathrm{av}}$ of $872 \mathrm{~nm}(\mathrm{AD}=5.4 \%)$. For plate-grown spores, length varied from $1.7-2.7 \mu \mathrm{m}\left(\mathrm{L}_{\mathrm{av}}=2.17 \mu \mathrm{m}, \mathrm{AD}=8.3 \%\right)$, and height varied between $740-1080 \mathrm{~nm}$ $\left(\mathrm{H}_{\mathrm{av}}=937 \mathrm{~nm}, \mathrm{AD}=5.3 \%\right)$.

The differences in size between the smallest and largest spores within a single population were $\sim 1.3 \mathrm{x}$ for width and $\sim 1$.6x for length in case of solution-grown spores, and $\sim 1.5 \mathrm{x}$ for width and $\sim 1.6 \mathrm{x}$ for length in case of plate-grown spores. The differences in average spore dimensions for the same species grown by two different methods were in the range of 7-8\%. Spore size variations were much more pronounced when compared among different spore-forming species. The average dimensions of $B$. thuringiensis

spores were $30-50 \%$ larger than the dimensions of B. atrophaeus spores ${ }^{20}$. Extensive size/height distribution measurements are not reported here for B. cereus spores; however 
average spore height and size measurements of 25 spores were similar to the distributions observed for B. thuringiensis spores (data not shown).

Exosporium As illustrated in Fig.1, both B. thuringiensis and B. cereus native spores were enclosed within an exosporium sacculus (indicated with the letter $E$ in Fig. 1), which was larger than the dimensions of the spore body. All B. cereus spores studied and many B. thuringiensis spores exhibited ridges (indicated with white arrows in Fig. 1). These ridges extended along the long axis of the spore and had heights of 20-50 nm. Similar ridges were previously noted in electron microscopy ${ }^{23,27}$ and AFM studies of bacterial spores ${ }^{18,20}$. We have previously demonstrated that B. atrophaeus spores decreased in size by $\sim 12 \%$ during a transition from a fully hydrated to an air-dried state ${ }^{20}$. This shrinkage was apparently due to a contraction of the spore core and cortex ${ }^{20,37}$. In a desiccated state, the decreased spore core/cortex dimensions resulted in the formation of spore surface ridges ${ }^{20}$. This strongly suggests that the major ridges found on exosporium-encapsulated air-dried spores, e.g. B. thuringiensis, B. cereus and B. anthracis (not shown here) are formed due to the folding of the spore coat rather than the much more flexible exosporium. The outer coat of B. thuringiensis spores typically exhibited considerably less ridge formation when compared with B. atrophaeus and $B$. cereus spores. This finding suggests that the outer spore coat elastic properties may vary among spore-forming species. Apart from ridge formations on the coat, numerous shallow wrinkles with a height of 2-8 $\mathrm{nm}$ were also seen on the surface of the exosporium, which was patchily associated with the spore coat.

In addition to significant amounts of lipid (18\%) and carbohydrate (20\%), and smaller amounts of other components including amino sugars ${ }^{38,39}$, the major part of the 
exposporium is reported to consist of two glycoprotein components ${ }^{40,41}$. It is constructed out of an inner part with $3-4$ thin hexagonal crystalline layers, and an amorphous, hirsute layer on the outside ${ }^{22,27}$. The $B$. thuringiensis crystalline lattice structure belongs to the $\mathrm{p} 6$ hexagonal space group with a repeat of $8.0 \mathrm{~nm}^{27}$.

The reported thickness of $B$. thuringiensis exosporium, as derived from EM thin sections, is $20 \mathrm{~nm}$ for 4 crystalline layers and $30 \mathrm{mn}$ for the hirsute layer, for a total of 50 $\mathrm{nm}^{22}$. In the same study, B.anthracis exosporium thickness was measured to be $10 \mathrm{~nm}$ (crystalline layers) and $62 \mathrm{~nm}$ (hairy layer), for a total of $72 \mathrm{~nm}^{22}$. From EM freeze fractured B. thuringiensis and B. cereus spores, a thickness of $5 \mathrm{~nm}$ for the crystalline layers and $40-50$ for the hirsute layer (total $45-55 \mathrm{~nm}$ ) was estimated ${ }^{27}$. From images of thin sections of B.anthracis spores ${ }^{44}$, we estimated the crystalline layers to be $5-15 \mathrm{~nm}$ thick, while the hirsute layer varied between $15-20 \mathrm{~nm}$ (total $20-.45 \mathrm{~nm}$ ).

The thickness of substrate-bound exosporium patches as measured from the AFM height data varied in the range of 30-50 -nm. Note, that the accuracy of AFM height measurements is $\sim 0.5 \mathrm{~nm}^{1,2,36}$. Since these exosporium patches (see e.g. fig. 2a) consist of a top and bottom layer of a folded sacculum, this corresponds to an exosporium thickness of 15-25 nm. Furthermore, the estimate of the hirsute layer thickness can be done by measuring the width of the 'footstep' seen at the edge of substrate-bound exosporium. This footstep, indicated with black arrows in Fig. 2a, represents the hairy layer protruding at the point were the solid, crystalline exosporium sacculus is folded flat. From this, the hirsute layer is measured to have a thickness of $30-35 \mathrm{~nm}$, which corresponds with earlier EM measurements ${ }^{22,27}$. We could not discern the crystalline 
layers along the edge of the exosporium patches to estimate their thickness in a similar way.

Apart from the $30-35 \mathrm{~nm}$ hirsute layer, the exosporium surface is frequently decorated with surface appendages ${ }^{26,45-47}$. These structures are most often described as hollow tubular filamentous extensions similar to pili of enterobacteria. The reported dimensions are variable but are in the range of 0.03 to $0.6 \mu \mathrm{m}$ in width and 1.5 to $3.0 \mu \mathrm{m}$ in length. These structures are most frequently described in the closely related B. cereus, B. anthracis and B. thuringiensis group. The appendages appear to be composed of highly acidic monomeric subunits of 2-5 kDa. The number of appendages per spore varies from three to more than twenty. These filaments could be of importance for spore attachment to surfaces or ligands. Spores containing surface appendages are able to aggregate at lower ionic strength and to attach more avidly to surfaces than pili-less spores. Spores can be detached from surfaces by treatment with $\mathrm{Ba}^{2+}$ or EDTA, which disrupts the organization of surface appendages ${ }^{48}$. As illustrated in Fig. 2a, the filamentous exosporial appendages appeared to be attached to the outer surface of the exosporium. Two types of appendages were typically observed. The first type (indicated with a white arrow in Fig. 2a and seen at higher magnification in b) appeared to be tubular with a diameter and length in the range of 8-12 nm and 400 $-1200 \mathrm{~nm}$ respectively. Other appendages, such as those indicated with a grey arrow in Fig. 2a, were 2.5-3.5 nm thick and typically 200-1600 nm long. Six to ten appendages were seen on the exosporium surface. Filamentous spore appendages have been reported in the electron microscopic studies of fungal and bacterial spores, including B. thuringiensis and B. cereus ${ }^{45}$. In the case of B. cereus spores, it was reported that the main component 
(> 70\%) of the filamentous appendages was protein ${ }^{47}$. It is reasonable to suggest that the appendages on the bacterial spores play a role in the attachment of spores to a substrate, as was established for appendages of fungal spores ${ }^{45}$.

High-resolution exosporium images, as illustrated in Fig. 2c, revealed that the $B$. thuringiensis exosporium outer surface is comprised of $\sim 8-10 \mathrm{~nm}$ beads/granules with a beads-on-a-string appearance. These subunits could represent exosporium proteins or their oligomers. The high-resolution structures of B. cereus spore exosporium, as illustrated in Figs. 2 d,e, were comprised of subunits with diameters of $12-14 \mathrm{~nm}$. The exosporium fine structures of these two species of bacterial spores appear to be distinctly different.

Cry protoxin crystal structure. Sporulation $B$. thuringiensis cells lyse and release both endospores and toxin crystals, which have a bipyramidal shape ${ }^{49}$. For some spore preparations these crystals were visualized by AFM (Fig. 3a, black arrow in Fig. 1a). The high-resolution crystalline structure of the surface layer is presented in Fig. 3b. The somewhat irregular appearance of the crystal surface layer rows is possibly probably a result of dehydration, however, fine structures comprising $\sim 8 \mathrm{~nm}$-diameter subunits (indicated with an arrow in Fig. 3b) could be discerned within the rows. The size of these subunits corresponds to the diameter of the Cry protein protoxin with a molecular mass of 130-140 kDa, which is known to form protoxin crystals ${ }^{49}$.

Fully hydrated B. thuringiensis spore size. Upon hydration of air-dried spores (Fig.4a), the width of solution- and plate-grown $B$. thuringiensis spores increased by $\sim 16 \%$ and $10 \%$ respectively. The average width of fully hydrated $B$. thuringiensis spores was $1.04 \mu \mathrm{m}$ (standard deviation 12.4\%). 
An image of a fully hydrated $B$. thuringiensis spore attached to the substrate is presented in Fig. 4b, showing numerous folds and wrinkles on the surface of the exosporium sacculus. A high-resolution image of the hydrated B. thuringiensis exosporium is presented in Fig. 4c. It shows a distinctive granular appearance with subunit sizes of 8-11 nm.

In addition to imaging of freshly prepared (i.e. imaged within weeks) spore preparations, we studied a preparation of lyophilized spores that was hydrated, deposited and subsequently imaged. In this preparation, occasionally, “open” exosporium saccula of B. thuringiensis spores were visualized, including "empty”' saccula (Fig. 5a), as well as saccula in which the spore coat was exposed (Fig 5b). Additionally, spores completely devoid of exosporium were observed (Figs. 5c, d), which showed distinctive morphological differences. In some cases, the spore coat appears to be tightly attached to the underlying cortex, as illustrated in Fig. 5c. However, we observed a substantial number of spores that contained spore coats that appeared to be "oversized" compared to the core/cortex (Fig. 5d). The attachment of the spore coat to the cortex was inconsistent and resulted in the formation of folds (arrow in Fig. 5d). This lyophilized spore sample was kept for a several years in a vacuum desiccator with a reduced-pressure of $\sim 25 " \mathrm{Hg}$, which likely resulted in the damage of spore exosporium. The ability of AFM to visualize morphological changes in individual spores associated with their storage and preparation procedures suggests that this method could be used to establish biological signatures or "fingerprints" of microbial preparations. The ability of AFM to assist in reconstructing agent production and storage regimes provides a new microbial forensics capability. 
High-resolution structure of the $\boldsymbol{B}$. thuringiensis spore coat. Imaging of intact spores lacking the exosporium allowed, as is illustrated in Fig. 6, the first direct high-resolution visualization of the native outer coat structure of fully hydrated B. thuringiensis spores. The outer spore coat surface had a crystalline honeycomb structure composed of numerous domains. The lattice constant for the honeycomb structure was $\sim 9 \mathrm{~nm}$. The diameter of the holes/pits was 5 - $6 \mathrm{~nm}$. Honeycomb crystalline structures having similar lattice parameters, were observed in freeze-fracture electron microscopic studies of $B$. cereus and B. thuringiensis spores ${ }^{23,27}$. These crystalline structures were identified previously as pitted (P) layers.

In addition, in vitro AFM native spore imaging has revealed high-resolution structural features that were not previously reported. As illustrated in Fig. 6, the crystalline honeycomb structure is composed of numerous domains with varying orientations. Height information is preserved in AFM measurements allowing a detailed characterization of the crystalline layer surface topography. This structure had height variations of $\sim 20 \mathrm{~nm}$ (seen in Fig. $6 \mathrm{~b}$ as lighter and darker areas) which could reflect the underlying layer structure and may be one of the determinants of the domain structure. Two-dimensional nucleation of the honeycomb structure could take place in multiple points on the surface area of the outer spore coat, with different areas having variable height with respect to each other. Upon growth of nuclei, because of the uneven relief of the underlying surface, advancing fronts cannot merge flawlessly to form a single layer of honeycomb crystalline structure. Merger of these misaligned domains could result in the formation of domain boundaries. Mechanisms of domain formation are well known from crystallization and self-assembly studies ${ }^{50,51}$. Domain boundaries (as those indicated with 
an arrow in Fig. 6b) were observed with height differences between neighboring domains (Fig. 6b) as large as $3-4 \mathrm{~nm}$.

Dissection of spore ultrastructure by sonication. Sonication of intact spores was found to allow the removal of consecutive structural layers revealing the internal structure of the spore coat. As illustrated in Fig. 7a, sonication was able to remove portions of the $B$. thuringiensis exosporium revealing the underlying spore coat surface structure. At higher resolution, sonicated spores displayed either partially damaged (Fig. 7b) or intact (Fig. 7c) honeycomb structures that formed the outside layer of the spore coat.

As illustrated in Fig. 7f, sonication was found to remove the exosporium from Bacillus cereus spores allowing the visualization of the outer spore coat. This surface layer was formed by a "quilt" of rodlet domains that were disoriented with respect to each other. These 50 -200 nm domains were formed by parallel, 10 nm wide rodlets. Upon further removal of this rodlet structure by additional sonication, an underlying layer consisting of a honeycomb structure was revealed (Fig. 7g), with lattice parameters similar to those of B. thuringiensis spore coats (Fig. 6, 7c).

Similar rodlet quilt structures as those seen in Fig. $7 \mathrm{f}$ were observed in freezeetching electron microscopic studies of Bacillus cereus spores ${ }^{20}$. We have previously described the high-resolution architecture of rodlet structures forming the outer coat of $B$. atrophaeus spores $^{21}$. This B. atrophaeus rodlet layer is strikingly different from the rodlet structure of $B$. cereus spores seen in Fig. $7 f$. These species-specific spore outer coat structures appear to be caused by different mechanisms of nucleation and self-assembly of the rodlet crystalline layer ${ }^{21}$. 
The protein composition of the rodlet structures is not known. Self-assembly of the rodlet layer is guided by the surface chemistry of the underlying integument as well as by media chemistry during the sporulation process. In case of B. thuringiensis spores, rodlet structures were not observed as a part of the spore coat either by freeze-etching EM experiments ${ }^{23}$ or in the AFM studies reported here. However, as illustrated in Fig. 7h, patches of stray rodlets were observed adsorbed to the substrate. The width and thickness of these rodlets (Fig. 7h) was similar to those observed for B. atrophaeus and B. cereus spores. These observations suggest that a similar rodlet monomer participates in the formation of B. atrophaeus, B. cereus and B. thuringiensis crystalline layers. Rodlet monomers could self-assemble and form structures during the sporulation process not only on the spore inner coat, as is the case for B. cereus (Fig. 7f), but also in the mother cell cytoplasm or in bulk media following the release of the mature spore. Stray rodlet structures were observed in the case of B. thuringiensis as rodlet patches associated with the substrate (fig. 7h).

The AFM data reported here suggests that $B$. cereus and B. thuringiensis spore surfaces have species-specific ultrastructure and topology. These spore coat structural variations are mirrored in DNA and protein sequence variations in the spore core structural protein gene sspE (Fig.8) B. cereus $\mathrm{T}$ and B. thuringiensis israelensis have distinct sspE proteotypes and genotypes suggesting that they are divergent taxa. The variations in spore structural and genetic characteristic reported here, the panmictic genetic differentiation of $B$. cereus and B. thuringiensis natural populations ${ }^{29}$ and the sspE genetic separation of B. cereus and B. thuringiensis from B. anthracis ${ }^{32}$, are not fully consistent with the concept that these taxa are members of a single species ${ }^{31}$. 


\section{AKNOWLEDGEMENTS}

We thank Dr. Alexander McPherson for using atomic force microscopes in his laboratory at the University of California, Irvine, and Dr. Maurice Pitesky for providing samples of B. cereus and B. thuringiensis spores for preliminary experiments. This work was performed under the auspices of the U.S. Department of Energy by the University of California, Lawrence Livermore National Laboratory under Contract W-7405-Eng-48 and with support from DARPA. 


\section{References}

1. Binnig, G.; Quate, C.F.; Gerber, C. 1986. Atomic force microscope. Phys. Rev. Lett. 1986, 56, 930.

2. Hansma, P.K.; Cleveland, J.P.; Radmacher, M.; Walters, D.A.; Hillner, P.E.;

Bezanilla, M.; Fritz, M.; Vie, D.; Hansma, H.G.; Prater, C.B.; Massie, J.; Fukunage, L.; Gurley, J.V.; Elings, V. Appl. Phys. Lett. 1984, 64, 738.

3. Karrasch, S., R.; Hegert, J.; Hoh, W.; W. Baumeister, W.; Engel, A. Proc. Nat. Acad. Sci. USA 1994, 91, 836.

4. Engel, A.; Muller, D.J. Nature Struct. Biol. 2000, 7, 715.

5. Hörber, J.K.H.; Miles, M.J. Science 2003, 302, 1002.

6. Schabert, F.A.; Henn, C.; Engel, A. Science 1995, 268, 92.

7. Kim, H.; Garavito, R.M.; Lal, R. Coll. Surf. B: Biointerfaces 2000, 19, 347.

8. Muller, D.; Engel, A. J. Mol. Biology 1999, 285, 1347.

9. Stolz, M.; Stoffler, D.; Aebi, U.; Goldsbury, C.. J. Struct. Biol. 2000, 131, 171.

10. Shao, Z., D. Shi, D.; Somlyo, A.V. Actin. Biophys. J. 2000, 78, 950.

11. Malkin, A.J.; McPherson, A.; Gershon, P.D. J. Virol. 2003, 77, 6332.

12. Malkin, A.J.; Plomp, M.; McPherson, A. In DNA Viruses: Methods and Protocols; Lieberman, P.M. Ed, Humana Press Inc. Totowa, New Jersey, 2004; p 85.

13. Kuznetsov, Yu.G.; Malkin, A.J.; Lucas, R.W.; Plomp, M.; McPherson, A. J. of Gen. Virol. 2005, 82, 2025. 
14. Kuznetsov, Yu.G.; Victoria, J.G.; Robinson, Jr. W.E.; McPherson, A. J. Virology 2003, 77, 11896.

15. Plomp, M.; Rice, M.K.;Wagner, E.K.; McPherson, A.; Malkin, A.J.. Amer. J. Pathol. 2002, 160, 1959.

16. Dufrêne, Y.F.; Boonaert, C.J.P.; Gerin, P.A.; M. Asther, M.; Rouxhet, P.G. J Bacteriol. 1999, 181, 5350.

17. Dufrene Y.F. Nature Reviews. Microbiol. 2004, 2, 451.

18. Chada, V.G.R.; Sanstad, E.A.; Wang, R.; Driks, A. J. Bacteriol. 2003, 185, 6255.

19. Sokolov, I.Yu.; Firtel, M.;Henderson, G.S. J. Vac. Sci. Technol. 1996, A14, 674.

20. Plomp, M., Leighton, T.J.; Wheeler, K.E.; Malkin, A.J.Biophysical.J. 2005, 88, 603.

21. Plomp, M., Leighton, T.J.; Wheeler, K.E.; Malkin, A.J.Microbiolog, 2005, in press.

22. Gerhardt,P.; Ribi, E. 1964. J. Bacteriol. 1964, 88, 1774.

23. Aronson, A.I.; Fitz-James, P. Bacteriol. Rev. 1976, 40, 360.

24. Holt, S.C.; Leadbetter, E.R. Bacteriol Rev. 1969, 33, 346.

25. Ohye, D.F.; Murrel, W.G. J. Bacteriol.1973, 115, 1179.

26. Desrosier, J.P.; Lara, J.C. J. Gen. Microbiol. 1984, 130, 935.

27. Wehrli, E.; Scherrer, P.; Kubler, O. Europ. J. Cell Biol. 1980, 20, 283.

28. Drobniewski, F.A. Clin. Microbiol. Rev. 1993, 6, 324.

29. Vilas-Boas G.; Sanchis, V.;Lereclus, D.; Lemos, M.V.; Bourguet, D. Appl. Environ. Microbiol. 2002, 68, 1414.

30. de Maagd, R.A.; Bravo, A; Berry, C.; Crickmore, N.; Schnepf, H.E.. Annu. Rev. Genet. 2003, 37, 409. 
31. Helgason E.; Okstad, O.A.; Caugant, D.A.; Johansen, H.A.; Fouet, A.; Mock, M.; Hegna, I.; Kolsto, A.B. Appl. Environ. Microbiol. 2000, 66, 2627.

32. Kim K.; Seo, J.; Wheeler, K.; Park, C.; Kim, D.; Park, Kim, S.W.; Chung, S.;

Leighton, T. FEMS Immunol. Med. Microbiol. 2005, in press.

33. Longchamp, P.; Leighton, T. Lett. Appl. Microbiol. 2000, 31, 242.

34. Nicholson, W.L.; Setlow, P. In Molecular Biological Methods for Bacillus Harwood, C.R.; Cutting, S.M. Eds.; John Wiley \& Sons, Chichester, West Sussex (UK) 1990; p.391.

35. Leighton, T.; Doi, R.H .J. Biol. Chem. 1971, 246, 3189.

36. Magonov, S.N. In Encyclopedia of Analytical Chemistry, Meyers, R., Eds. John Wilet \&Sons Ltd, 2004; p.1.

37. Driks, A. Proc. Natl. Acad. Sci. USA. 2003, 100, 3007.

38. Matz, L.L.; Beaman, T.C.; Gerhardt, P. J. Bacteriol. 1970, 101, 196.

39. Takumi, K.; .Kinouchi, T.; Kawata, T. Microbiol. Immunol. 1979, 23, 443.

40. Garcaia-Patrone, M.; Tandecarz, J.S. Mol. Cell. Biochem. 1995, 145, 29.

41. Quinlan, J. J.; Foegeding, M. Appl. Environ. Microbiol. 1997, 63, 482.

42. Masuda, K.; Kawata, T.; Takumi, K.; Kinouchi, T. Microbiol. Immunol. 1980, 24, 507.

43. Warth, A. D. Adv. Microbiol. Physiol. 1978, 17, 1.

44. Driks, A. Trends in Microbiol. 2002, 10, 251.

45. Hachuka, Y.; Kozuka, S.; and Tsujikawa, M. Microbiol. Immunol. 1984, 28, 619.

46. Smirnova, T.A.; Kulinich, L.I.,; Galperin, M.Y.; Azizbekyan, R.R. FEMS Microb. Lettr. 1991, 90, 1.

47. Kozuka,S. and Tochikubo, K. Microbiol. Immunol. 1985, 29, 21.

48. Panessa-Warren B.J.;Tortora,G.T.; Warren, J.B.Tissue Cell. 1979, $29,449$. 
49. Li,J., J.; Carrol, J.; Ellar, D.J. Nature 1991, 353, 815.

50. Chernov, A.A. Modern Crystallography III. Crystal Growth. Springer-Verlag: Berlin, 1984.

51. Malkin, A.J.;Thorne, R.E. In Methods: A Companion to Methods in Enzymology. Macromolecular Crystallization. McPherson, A. Ed.; Elsevier Inc, San Diego, 2004, p.273. 


\section{Figure legends}

Figure 1. AFM images of air-dried B. thuringiensis (a) and B. cereus (b) spores. Surface ridges, extending along the entire spore length are indicated with white arrows in (a) and (b). In (a) a bipyramidal crystal is indicated with a black arrow. Scan areas are: (a) $2.8 \mathrm{x}$ $2.8 \mu \mathrm{m}$; (b) $1.7 \times 1.7 \mu \mathrm{m}$.

Figure 2. (a) AFM image of the $B$. thuringiensis exosporium showing a footstep with numerous thin hair- like appendages (indicated with black arrows) and longer and thicker appendages (indicated with gray and white arrows). In (b) a high-resolution image of a long appendage. (c-e) High-resolution images of $B$. thuringiensis exosporium (c) and $B$. cereus (d,e) spores. Scan areas are: (a) 1.1 x $1.1 \mu \mathrm{m}$; (b) 640 x 160 nm, (c) 900 x 450 nm and (d) $1.0 \times 1.0 \mu \mathrm{m}$; and (e) $500 \times 500 \mathrm{~nm}$.

Figure 3. (a) AFM image of the insecticidal protoxin crystal formed during $B$. thuringiensis sporulation. (b) Surface morphology of the protoxin crystal, $\sim 8 \mathrm{~nm}$ subunits are indicated with arrows. Scan areas are: (a) .4.0 x $4.0 \mu \mathrm{m}$ and (b) 450 x $450 \mathrm{~nm}$.

Figure 4. (a,b) AFM images of fully hydrated B. thuringiensis spores. (c) A highresolution image of the exosporium. Scan areas are: (a) 5.0 x $5.0 \mu \mathrm{m}$; (b) 4.5 x $4.5 \mu \mathrm{m}$; and (c) $600 \times 300 \mathrm{~nm}$.

Figure 5. AFM images of partially damaged $B$. thuringiensis spores recovered from lyophilized spore preparations. (a) An open, empty exosporium sacculus. (b-d) Spores 
with partially (b) or completely (c,d) removed exosporium. The exosporium and spore coat are indicated with E and C, respectively. Scan areas are: (a) 2.0 x $1.4 \mu \mathrm{m}$; (b) $2.1 \mathrm{x}$ $1.6 \mu \mathrm{m}$, (c) $2.1 \times 1.05 \mu \mathrm{m}$ and (d) $2.8 \times 1.3 \mu \mathrm{m}$.

Figure 6. (a-c) AFM images showing the honeycomb outer coat crystalline structure of B. thuringiensis spores. (b) High-resolution image of the area indicated with a rectangle in (a). Two domains with different orientations of the crystalline lattice are indicated with triangles. A stacking fault is indicated with an arrow; (c) High-resolution image of the area indicated with a rectangle in (b). Scan areas are: (a) $1.5 \times 0.75 \mu \mathrm{m}$; (b) $700 \times 350$ $\mathrm{nm}$, (c) $260 \times 130 \mathrm{~nm}$.

Figure 7. AFM images showing crystalline structures of the spore coat of sonicated $B$. thuringiensis (a-c) and B. cereus (d-g) spores. (a,b) The B. thuringiensis exosporium (E) is partially removed by sonication revealing the spore coat $(C)$. In the zoomed-in image (b) the high-resolution honeycomb structure of the spore coat is seen, as is in (c); $(\mathrm{d}, \mathrm{f})$ Complete removal of the $B$. cereus exosporium by sonication reveals the surface rodlet layer formed by multiple misoriented domains that covers the outer coat (f); (e,g) Removal of this exterior rodlet patchwork by further sonication reveals the underlying honeycomb structure in zoomed-in image (g). Two remaining rodlets are indicated with an arrow in (g). (h) Networks of self-assembled extrasporal rodlet structures, that are seen adsorbed to the substrate during imaging of B. thuringiensis spore samples. Scan areas are: (a) $2.7 \times 2.7 \mu \mathrm{m}$; (b) $400 \times 400 \mathrm{~nm}$, (c) $300 \times 300 \mathrm{~nm}$; (d) $4.0 \times 2.0 \mu \mathrm{m}$; ( e) 4.0 x $2.0 \mu \mathrm{m}$; (f) 310 x $310 \mathrm{~nm}$; (e) 310 x $310 \mathrm{~nm}$; and (h) 1.6 x $1.6 \mu \mathrm{m}$. 
Figure 8. (A) DNA sequence alignment of $B$. thuringiensis israelensis and $B$. cereus T sspE coding sequences. (B) Protein sequence alignments of $B$. thuringiensis israelensis and B. cereus T SspE amino acid sequences. 


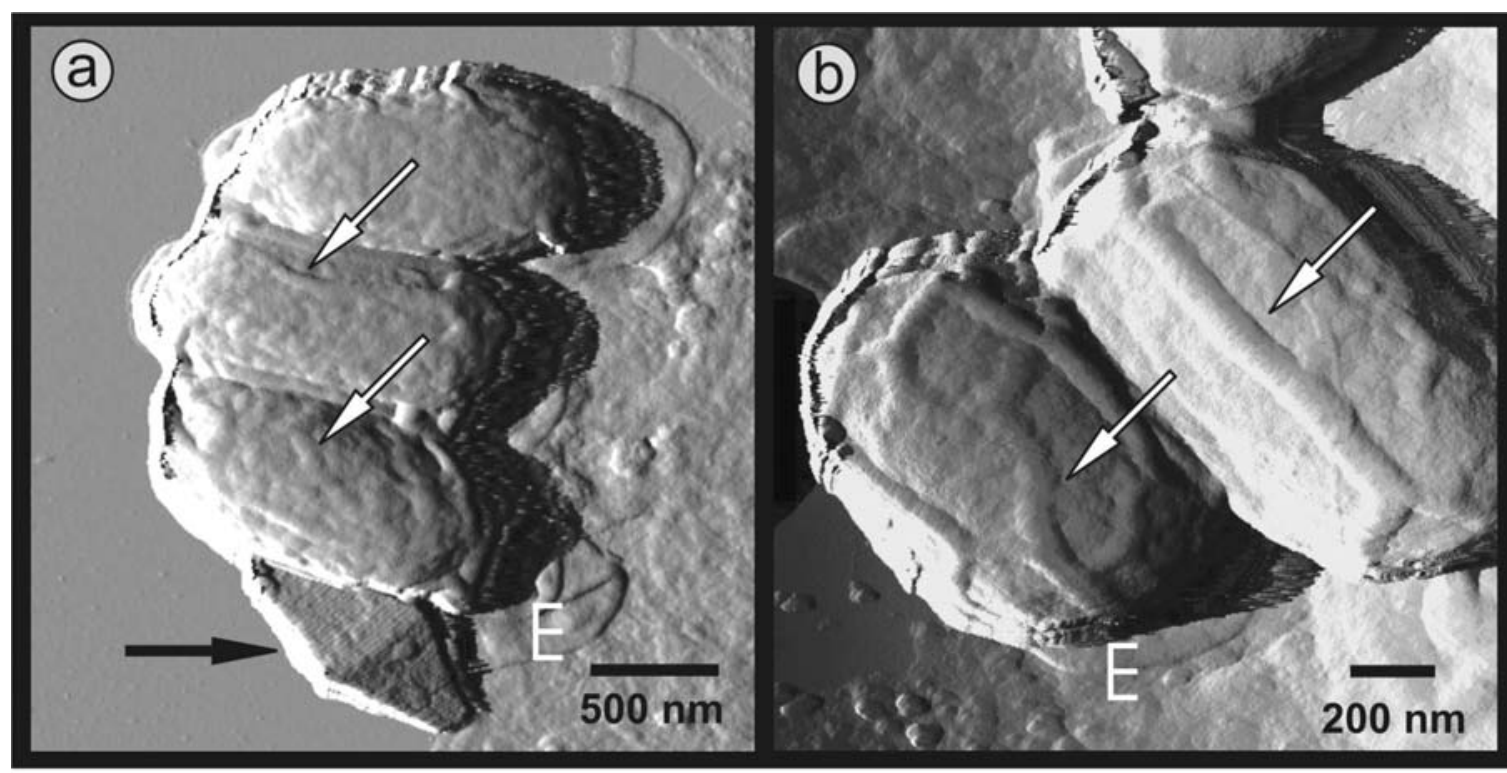

Figure 1 


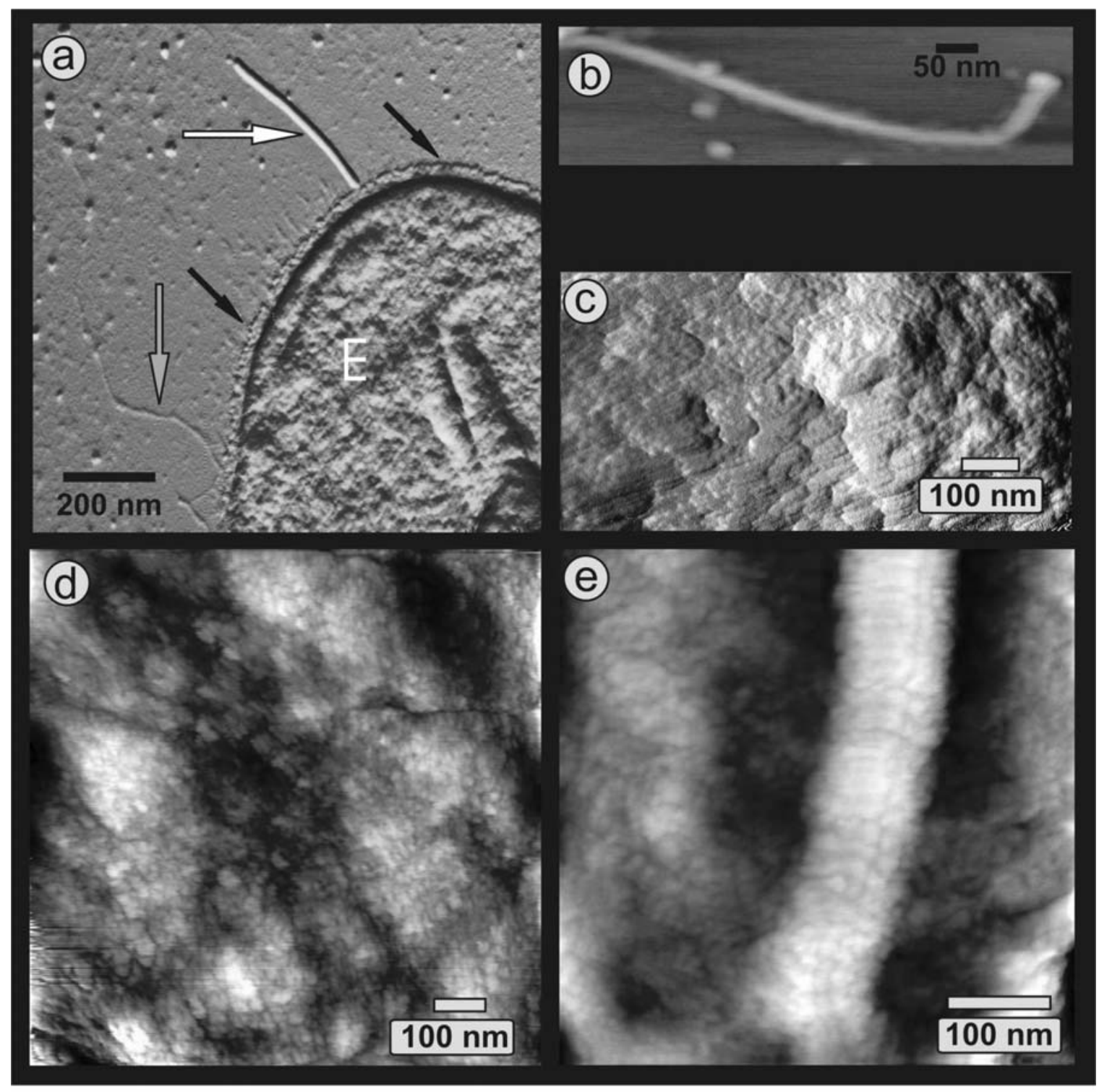

Figure 2 


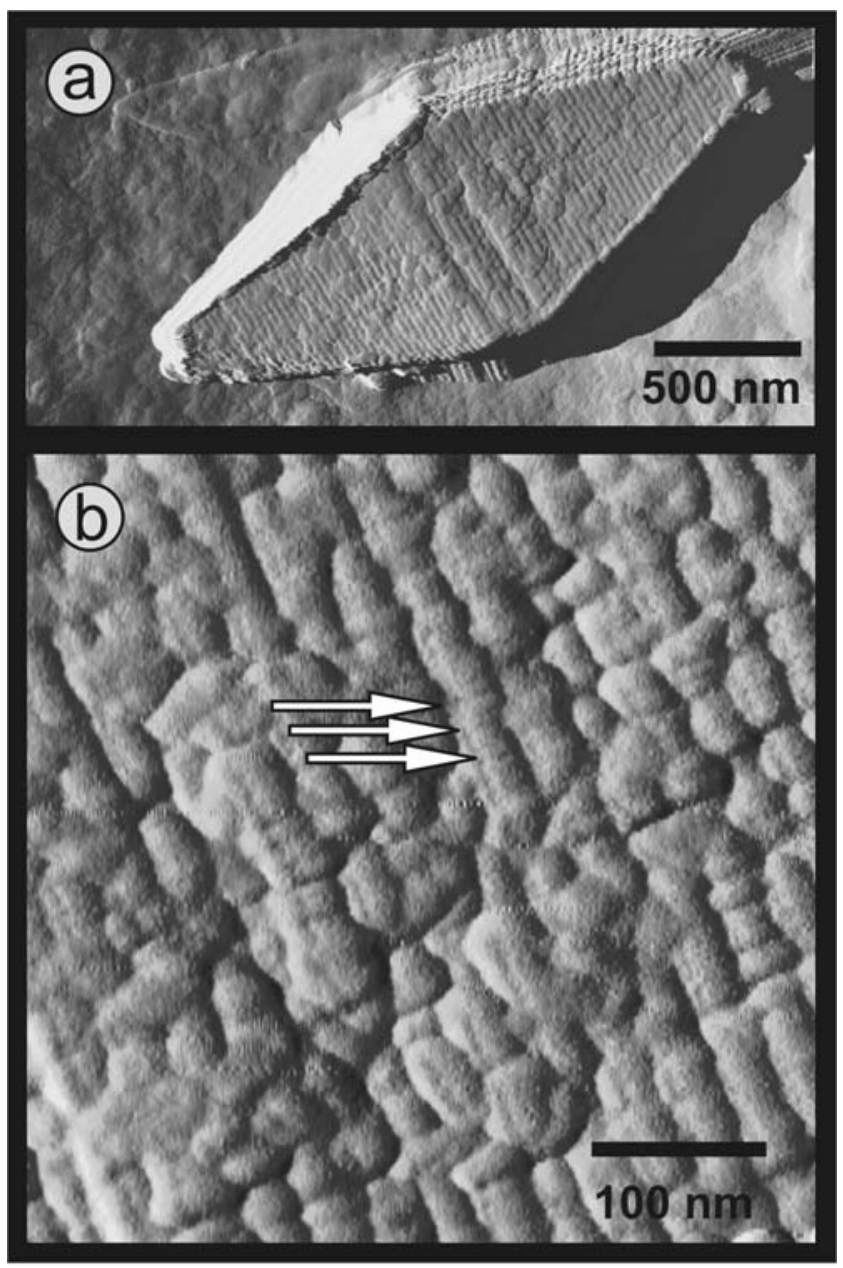

Figure 3 


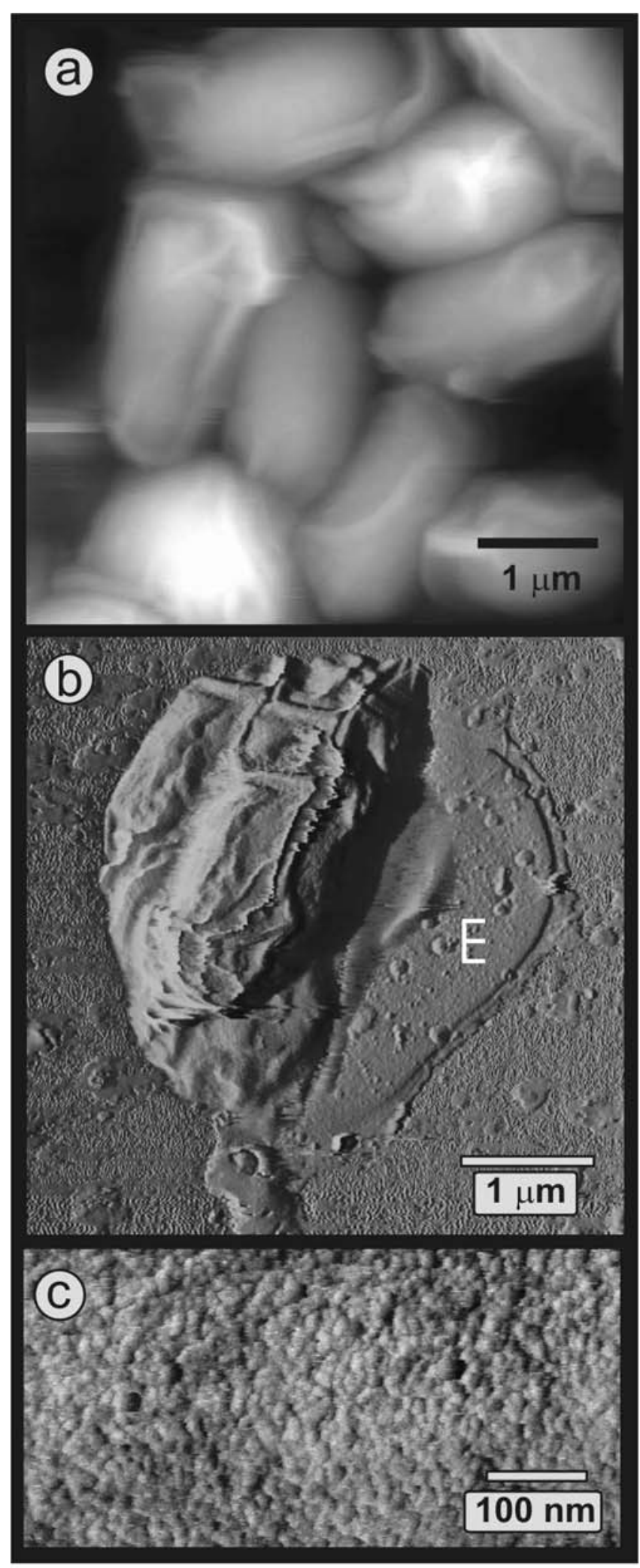

Figure 4 


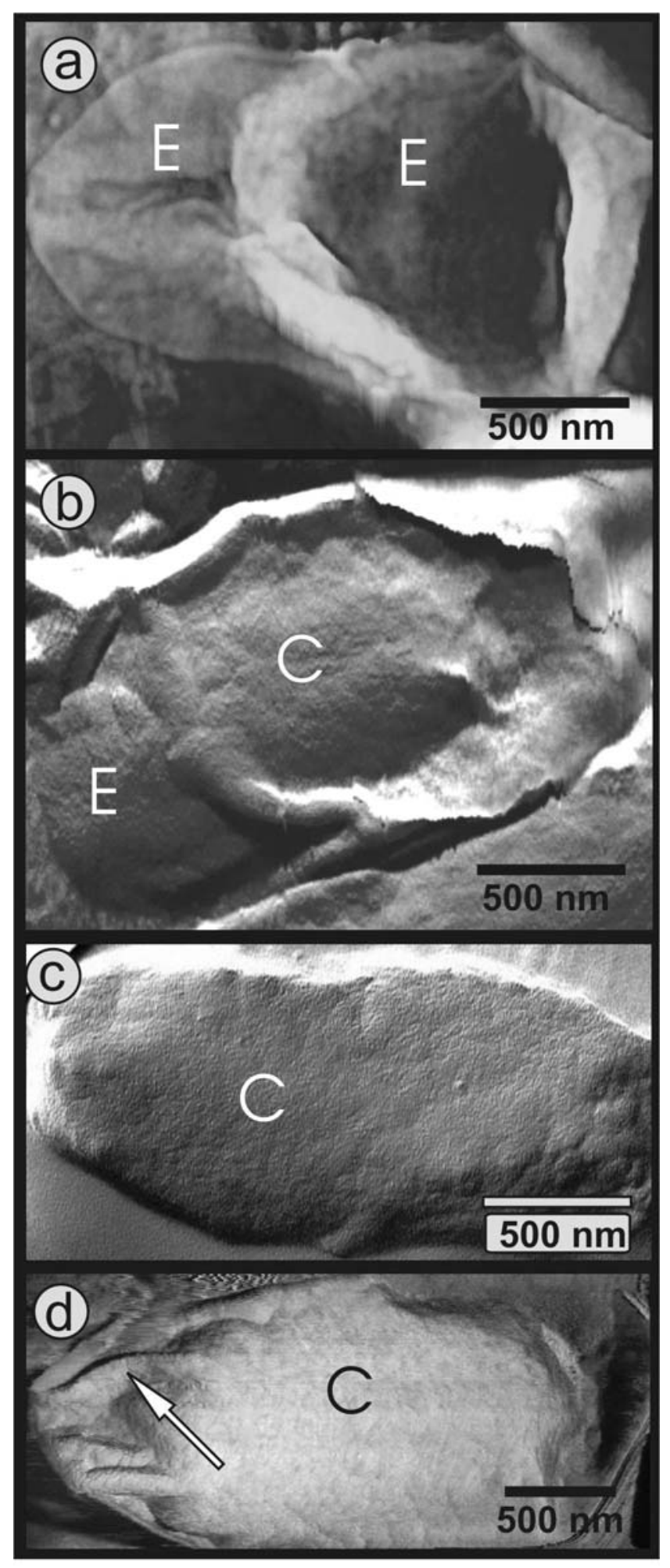

Figure 5 


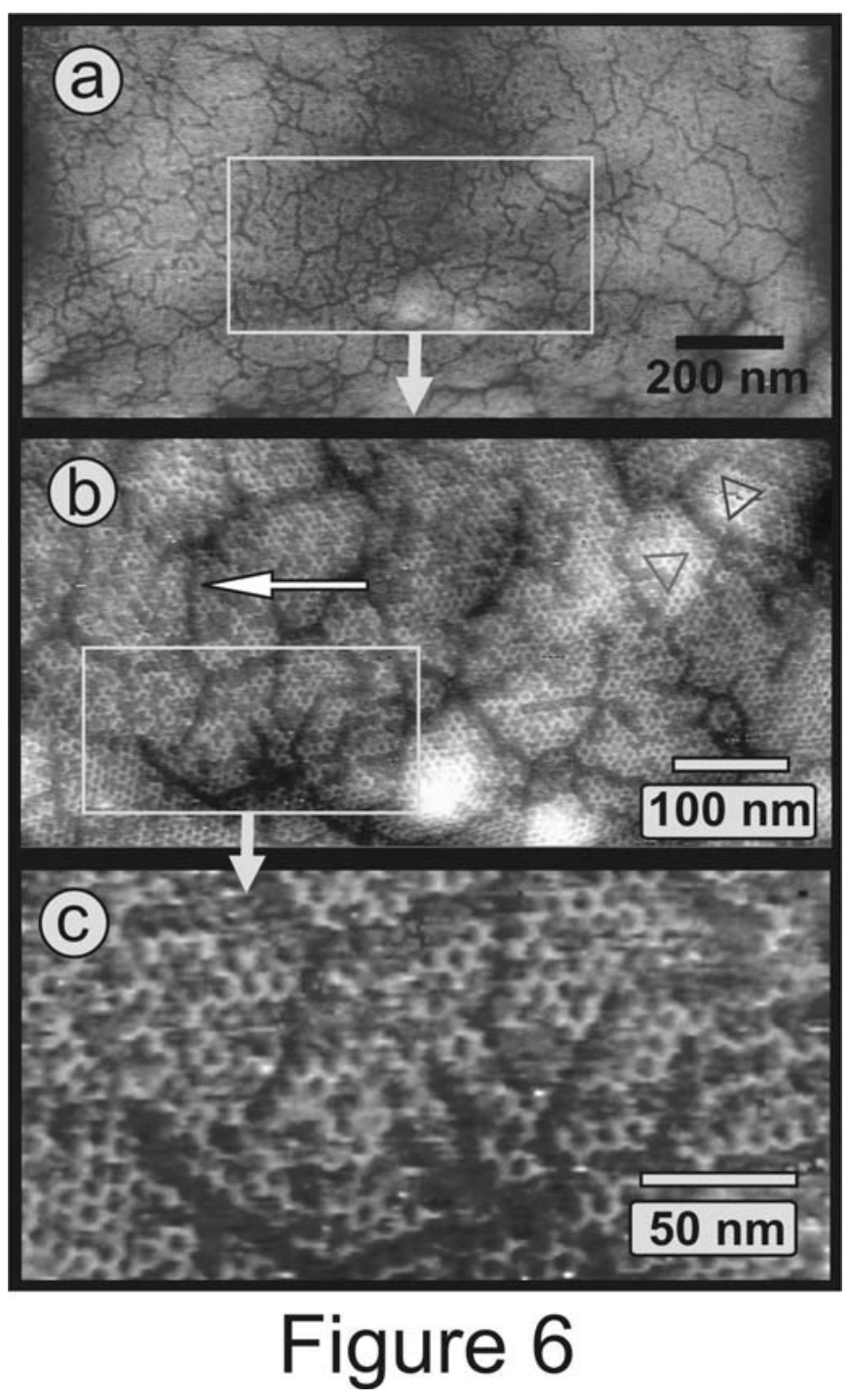




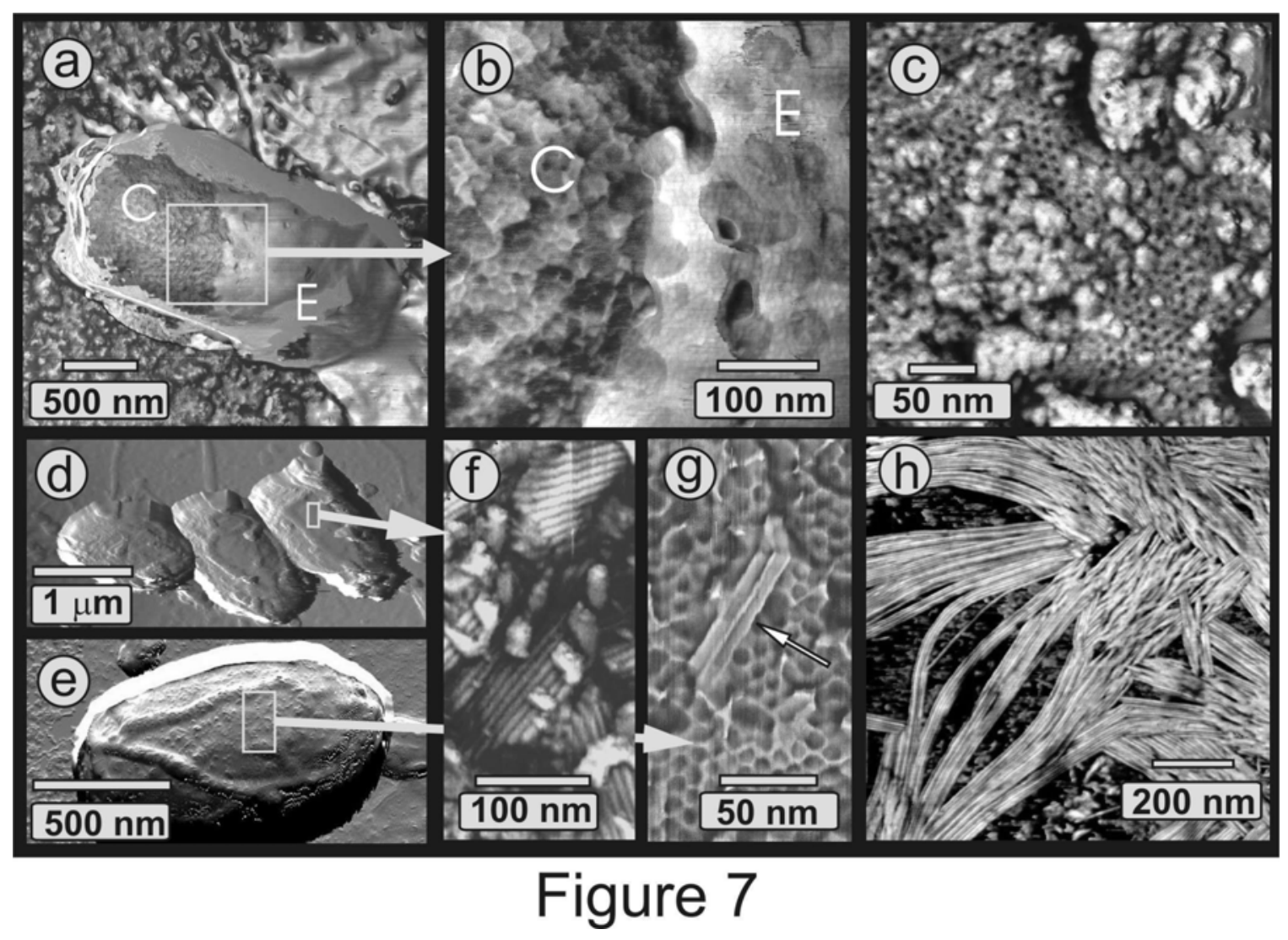


A

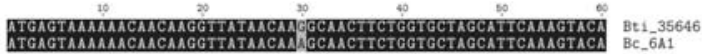

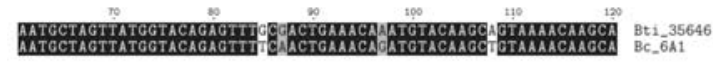

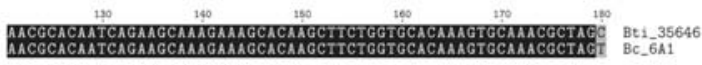

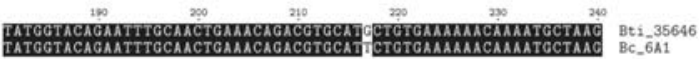

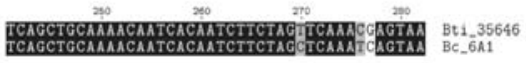

B

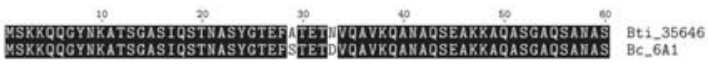

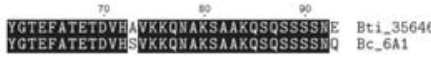

$\mathrm{X}$ non conserved

$\mathrm{X}$ similar
$\mathrm{X}$ conserved
$\mathrm{X}$

Figure 8 